\title{
Central Sleep Apnea in Motor Neuron Disease with “Two-Can" Effect
}

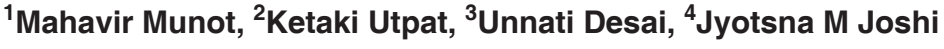

\begin{abstract}
Motor neuron disease (MND) is an umbrella term used to signify an assorted group of progressive neurologic disorders that cripple upper and lower motor neurons with axonal loss and gliosis. The MND classically presents as progressive muscle weakness, muscle atrophy, spasticity, and bulbar symptoms like dysarthria and dysphagia. The disease has a solemn course and a poor prognosis. Respiratory jeopardy is a run-of-the-mill phenomenon in this disease. It culminates from the combination of weakness of the pharyngeal and laryngeal muscles and the major respiratory muscles like diaphragm and intercostals. The upper airway flaccidity engenders the perpetuation of sleep disordered breathing (SDB) while the respiratory muscle weakness triggers lung physio-dynamic alterations and chronic respiratory failure. Hence, spirometry and polysomnography are vital tools in the diagnostic work-up. We hereby present an intriguing case of a patient with MND manifesting both these aspects of SDB and a peculiar spirometry pattern of a "two-can" effect!
\end{abstract}

Keywords: Central sleep apnea, Flow-volume loop, Spirometry.

How to cite this article: Munot M, Utpat K, Desai U, Joshi JM. Central Sleep Apnea in Motor Neuron Disease with "Two-Can" Effect. Indian J Sleep Med 2017;12(4):73-76.

Source of support: Nil

Conflict of interest: None

\section{INTRODUCTION}

Motor neuron disease betokens a group of disorders that selectively affect upper and/or lower motor neurons. Amyotrophic lateral sclerosis (ALS) is the most bourgeois MND. It can occur in sporadic or familial form, the sporadic being more common. The commonly encountered symptoms include hyperreflexia, spasticity, Babinski sign and bulbar symptoms like dysphagia and dysarthria. ${ }^{1} \mathrm{~A}$ progressive ramification in the areas involved is seen. Virtually any muscle group can be involved; however, the respiratory group of muscles is its most common sitting. Involvement of the respiratory system can occur at an initial or later stage of the disease unfolding. The

${ }^{1}$ Resident, ${ }^{2}$ Assistant Professor, ${ }^{3}$ Associate Professor, ${ }^{4}$ Professor and Head

${ }^{1-4}$ Department of Pulmonary Medicine, Topiwala National Medical College \& B.Y.L. Nair Ch. Hospital, Mumbai, Maharashtra, India

Corresponding Author: Jyotsna M Joshi, Professor and Head Department of Pulmonary Medicine, Topiwala National Medical College \& B.Y.L. Nair Ch. Hospital, Mumbai, Maharashtra, India Phone: +912223027642, e-mail: drjoshijm@gmail.com upper airway and respiratory muscles may be involved in a variable combination and severity. Patients present with progressive exertional dyspnea, inability to sleep in supine position and symptoms suggestive of SDB. ${ }^{2}$ Sleep disordered breathing is a frequent phenomenon in MND and stems from upper airway suppleness and the mechanical disadvantage of the diaphragm. Nocturnal hypoventilation and sleep fragmentation are the basics culprits leading to hypoxia and neurocognitive damage. It has a pessimistic impact on the quality of life as well as the survival. Hence, opportune diagnosis is crucial to prevent irrevocable end organ affection. Spirometry is a simple and easily accessible pulmonary function test, which aids in clinching the diagnosis by its classical appearance. We present the case report of a patient of MND with SDB and central sleep apnea (CSA). On evaluation, spirometry showed a "two-can" effect and worsening of lung function in supine position.

\section{CASE REPORT}

A 60-year-old man, nonsmoker, was referred to us from a peripheral hospital in view of breathlessness. He complained of dyspnea on exertion of modified Medical Research Council (MMRC) grade I since 2 to 3 years which progressed to grade II since 6 months. General examination was within normal limits. Patient was advised investigations but was lost to follow-up in view of his domestic problems. He reported 2 months later with progression of dyspnea to grade III and disproportionate breathlessness on lying down. Now, he also complained of difficulty in his day-to-day activities like combing, buttoning-unbuttoning of shirt and difficulty in swallowing since 2 months. On enquiry, he gave a history of wasting of hand muscles since 6 months. Patient also had a history of systemic hypertension since 7 years and was on treatment with oral antihypertensive drugs. On neurological examination, the patient had a stooped posture with masseter muscle wasting, thenar and hypothenar muscle wasting, mini opsomyoclonus of both hands and brisk reflexes. The respiratory system examination was within normal limits. The baseline saturation of the patient measured with a pulse oximeter $\left(\mathrm{SpO}_{2}\right)$ was normal; however, there was a desaturation to $80 \%$ with paradoxical thoracoabdominal movements on lying supine. The routine 


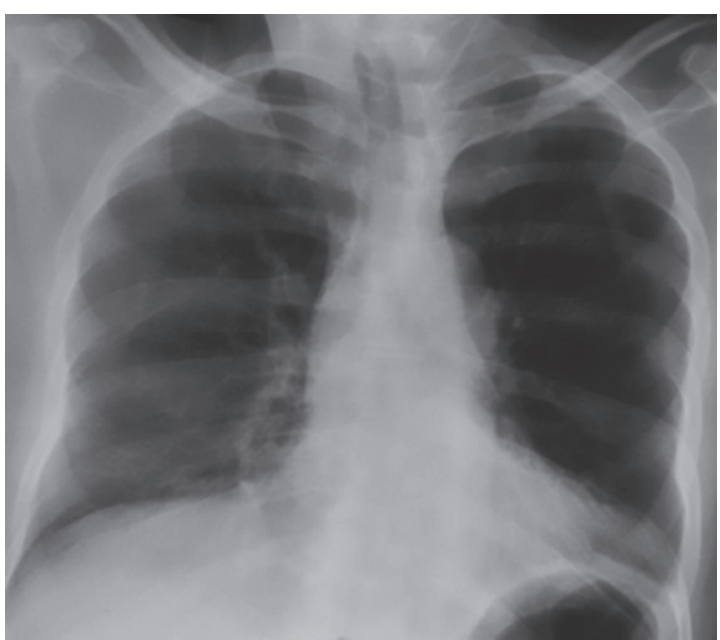

Fig. 1: Chest X-ray showing bilateral elevated hemidiaphragm

hematological and biochemical blood investigations were within normal limits. Arterial blood gas analysis was normal. Thyroid function tests were normal. Chest radiograph was suggestive of bilateral elevated diaphragm (Fig. 1). High-resolution computed tomography of chest showed patchy ground glass opacities with smooth septal thickening in apex with subcentimeter size nodules in apices. Mild eventration of both hemidiaphragms with subsegmental and passive atelectasis of underlying lung with dilated left ventricle was also noted. Two-dimensional echocardiography was suggestive of hypertensive heart disease. With a suspicion of a neurological disease, the patient was evaluated with an electromyography and nerve conduction velocity study which showed acute and chronic denervation of $\mathrm{C} 5$ to $\mathrm{C} 8$ and $\mathrm{T} 1$ nerves, with site of lesion being anterior horn cells/nerve roots. Spirometry was suggestive of forced expiratory volume in the first second (FEV1) of $1.25 \mathrm{~L}(44 \%)$, forced vital capacity (FVC) of $1.85 \mathrm{~L}(53 \%)$ with FEV1/FVC ratio of $68 \%$ in sitting position. While in supine position, they were reduced to FEV1 of $0.42 \mathrm{~L}$ $(15 \%)$ and FVC of $0.89 \mathrm{~L}(25 \%)$. The flow volume loops (FV loop) revealed upper airway obstruction (UAO). The Empey's index was 8. The FV loop characteristically demonstrated a biphasic ("two-can" effect) expiratory loop along with fall in lung function in supine position (Fig. 2). To rule out SDB, polysomnography (PSG) was done which showed apnea-hypopnea index (AHI) of 29 with predominant CSA. Titration with bilevel positive airway pressure (PAP) showed reduction in CSA AHI.

The patient was diagnosed as a case of SDB, CSA with $\mathrm{UAO}$ due to MND.

\section{DISCUSSION}

The MND is a progressive and terminal group of disease that victimizes the motor neurons, or nerves, in the brain and spinal cord. It is a clinically and pathologically heterogeneous group which causes progressive degeneration of either upper or lower motor neurons. ${ }^{1}$ Upper motor neurons are the ones which originate in primary motor cortex and forms corticospinal and corticobulbar tracts. Lower motor neurons originate in brain stem and spinal cord and directly innervate skeletal muscles. Amyotrophic lateral sclerosis also known as Lou Gehrig's disease is most common of all MNDs. Most of ALS are sporadic and only 5 to $10 \%$ are familial. The disease particularly affects the middle-aged to old people with mean age of onset of around 58 years. ${ }^{3}$ Although MND is the third most common neurodegenerative disorder, it is standalone, rare with approximate incidence of 2 per lakh population where adequate epidemiological data exist. ${ }^{4,5}$ It presents as asymmetrical weakness and wasting of limb muscles with associated clinical evidence of corticospinal tract damage like brisk reflexes, extensor plantar and increased muscle

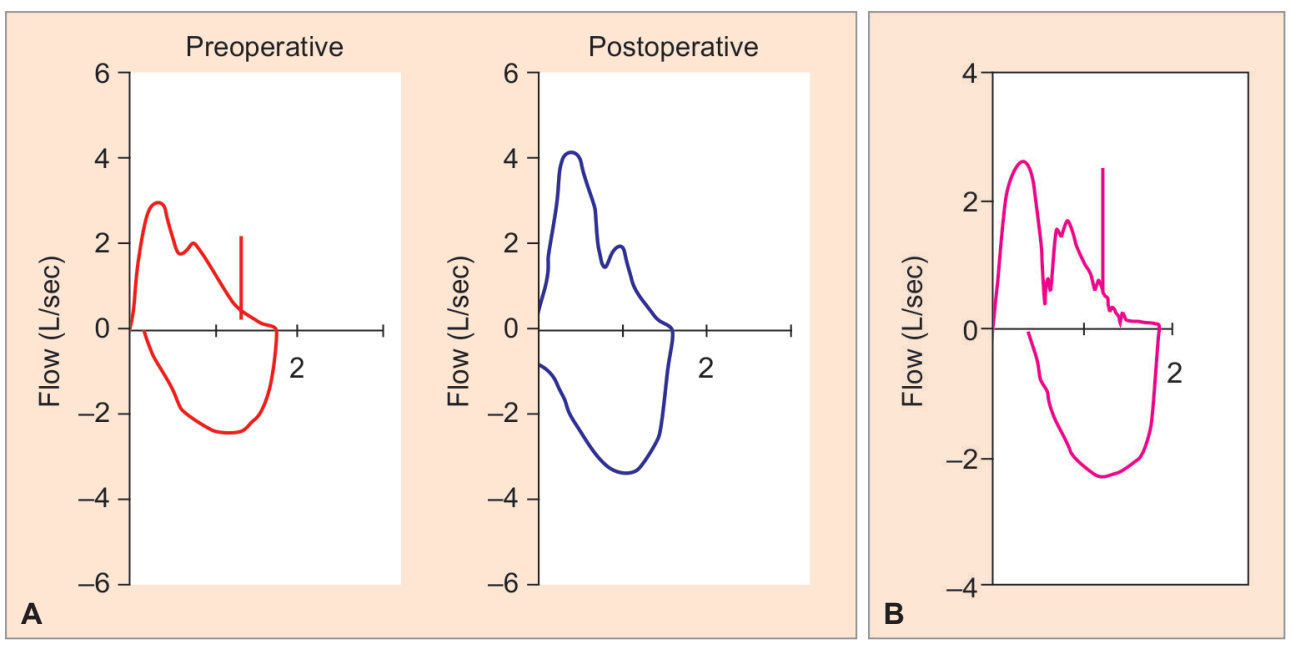

Figs 2A and B: (A) Spirometry in sitting position with classical "two-can" effect with pre- and post-bronchodilator FV loops. (B) Spirometry in supine position 
tone. Symptoms typically commence insidiously over months. During initial phase, disease usually involves one limb in the form of foot drop or wasting of hand muscles or it may present as combination of bulbar and corticobulbar symptoms in the form of brisk jaw jerk, dysphagia, dysarthria, tongue wasting, etc. These bulbar and corticobulbar symptoms are typically seen in women presenting after 50 years of age and it has poorer prognosis. ${ }^{1}$ Other forms of MND are primary lateral sclerosis, hereditary spastic paraparesis, progressive bulbar palsy, spinal muscular atrophy, X-linked spinobulbar muscular atrophy (Kennedy disease), and postpolio syndrome. Motor neuron degeneration can also be seen with other causes like viral infection, toxic insults, and immune-mediated disease. Motor neuron disease is a fatal disease where death typically occurs within 3 to 5 years of onset of disease. ${ }^{6,7}$

Respiratory muscle weakness is a run-of-the-mill occurrence in MND and the respiratory function significantly predicts both survival and quality of life. It is important to note that respiratory manifestations could sometimes be the sole presenting features of the disease even before the neurological manifestations set in. Our patient was a very good example of this occurrence. Hence, it is important to keep a high index of suspicion for this entity in the right clinico-radiological context. Respiratory complications arise from weakness of upper airway muscles which include pharyngeal and laryngeal muscles and respiratory muscles including diaphragm intercostal and accessory muscles leading to respiratory failure. Acute respiratory failure is leading cause of death in MND patients which is often precipitated by infective or aspiration pneumonia or impacted secretions. ${ }^{8,9}$ Diaphragm and other respiratory muscle weakness and ultimately diaphragmatic paralysis are common in MND and it leads to the development of respiratory failure and SDB. ${ }^{10}$ Diaphragmatic dysfunction leads to decreased survival as shown in one cohort study where median survival of MND patients with diaphragmatic dysfunction was 217 days while those without diaphragmatic dysfunction was 619 days. ${ }^{10}$ Dyspnea and nocturnal hypoventilation is caused by weakness of inspiratory intercostal muscles while weakness of expiratory muscles along with swallowing difficulties contributes to ineffectual cough and impaired secretion clearance which in turn increases risk of aspiration and aspiration pneumonitis. ${ }^{11}$ In patients of MND with respiratory muscle involvement, clinical examination may reveal paradoxical inward movement of abdomen during inspiration. "Respiratory pulse" may be seen during inspiration which is the visible contraction of scalene muscles. ${ }^{12,13}$ This particular breathing pattern decreases trans-diaphragmatic pressure and inspiratory time which in turn limits alveolar ventilation and leads to development of chronic respiratory failure. ${ }^{14}$ Various tests can assess respiratory muscle function. Simple test is the measurement of FVC in sitting and supine positions. It can fall up to $19 \%$ in healthy subjects and fall $>30 \%$ is pathognomonic of diaphragmatic palsy. ${ }^{15}$ This hallmark finding was seen in our patient too. Maximal inspiratory pressure (MIP) measures global inspiratory muscle strength and is closely related to diaphragmatic strength. Higher MIP values are associated with increased survival in MND patients. ${ }^{11}$ Hemi-diaphragm weakness can be identified using fluoroscopic sniff testing and thoracic ultrasonography. There can be raised hemidiaphragm and paradoxical upward movement of diaphragm in inspiration. Our patient too had elevated hemidiaphragms radiologically. Though not used routinely, diaphragm electromyography is most accurate in assessing diaphragm function and in the measurement of voluntary and twitch (after magnetic or electrical stimulation) trans-diaphragmatic pressures. Twitch trans-diaphragmatic pressure is the gold standard in predicting mortality, as it is independent of patient motivation and investigator skills. ${ }^{16}$ Monitoring respiratory functions helps the health professional and the person with MND to take decisions about management in a timely way. It is also important because effective management of respiratory function is likely to have a positive impact on quality of life for the person with MND. It may prevent an acute respiratory emergency, or inappropriate action being taken in the event of an emergency.

Spirometry plays a pivotal role in patients with MND. It is not only an important tool in assessing respiratory functions but it also can demonstrate peculiar exhibitions in the FV loop which may help in clinching the diagnosis. The "two-can" effect is defined as the biphasic nature of expiratory FV loop. This phenomenon has been hypothesized for sudden laryngeal muscle contractions in MND. Also when performed in supine and sitting position, spirometry shows decline in lung functions in supine position. Both these elements were observed in our case too. Sometimes, spirometry can show saw-tooth pattern due to tremors in laryngeal and pharyngeal muscles. ${ }^{17}$ These tremors persist during breath-holding which means that they are not caused by airway turbulence but by phasic innervation/denervation of muscles.

The SDB has been reported in 17 to $76 \%$ of patients with MND. ${ }^{18}$ The main mechanism of SDB is respiratory muscle weakness particularly diaphragm. The SDB occurs early in the course of disease even before daytime symptoms and chronic respiratory failure. ${ }^{19}$ Nocturnal hypoventilation is common in MND patients ${ }^{20-22}$ due to diaphragm intercostal and accessory neck muscle wasting which is exacerbated in REM sleep. ${ }^{20,23}$ Sleep studies of MND patients show periods of nonobstructive hypopneas and central apneas causing hypoventilation. ${ }^{20,24}$ Our patient also had SDB and CSA on his PSG. A timely diagnosis of SDB in these patients 
is exigent to prevent hypoxia-related neurocognitive and end-organ damage. Noninvasive ventilation is a promising modality of therapy in these patients by virtue of its action of dynamic splint to upper airways and also decreasing the work of breathing. ${ }^{2}$ Our patient was also treated with a bilevel PAP therapy with a favorable response.

\section{REFERENCES}

1. Talbot K. Motor neuron disease. Postgrad Med J 2002 Sep;78(923):513-519.

2. D'Cruz RF, Murphy PB, Kaltsakas G. Sleep disordered breathing in motor neuron disease. J Thorac Dis 2018 Jan;10(Suppl 1): S86-S93.

3. Ringel SP, Murphy JR, Alderson MK, Bryan W, England JD, Miller RG, Petajan JH, Smith SA, Roelofs RI, Ziter F, et al. The natural history of amyotrophic lateral sclerosis. Neurology 1993 Jul;43(7):1316-1322.

4. Traynor BJ, Codd MB, Corr B, Forde C, Frost E, Hardiman O. Incidence and prevalence of ALS in Ireland, 1995-1997: a population-based study. Neurology 1999 Feb;52(3):504-509.

5. Piemonte and Valle d'Aosta Register for Amyotrophic Lateral Sclerosis (PARALS). Incidence of ALS in Italy: evidence for a uniform frequency in western countries. Neurology 2001 Jan;56(2):239-244.

6. Chiò A, Mora G, Calvo A, Mazzini L, Bottacchi E, Mutani R; PARALS. Epidemiology of ALS in Italy: a 10-year prospective population-based study. Neurology 2009 Feb;72(8):725-731.

7. Alonso A, Logroscino G, Jick SS, Hernan MA. Incidence and lifetime risk of motor neuron disease in the United Kingdom: a population-based study. Eur J Neurol 2009 Jun;16(6):745-751.

8. Vrijsen B, Chatwin M, Contal O, Derom E, Janssens JP, Kampelmacher MJ, Muir JF, Pinto S, Rabec C, Ramsay M, et al. Hot topics in noninvasive ventilation: report of a Working Group at the International Symposium on Sleep Disordered Breathing in Leuven, Belgium. Respir Care 2015 Sep;60(9):1337-1362.

9. de Carvalho M, Matias T, Coelho F, Evangelista T, Pinto A, Luis ML. Motor neuron disease presenting with respiratory failure. J Neurol Sci 1996 Aug;139(Suppl):117-122.

10. Arnulf I, Similowski T, Salachas F, Garma L, Mehiri S, Attali V, Behin-Bellhesen V, Meininger V, Derenne JP. Sleep disorders and diaphragmatic function in patients with amytrophic lateral sclerosis. Am J Respir Crit Care Med 2000 Mar;161(3 Pt 1):849-856.

11. Schoser B, Fong E, Geberhiwot T, Hughes D, Kissel JT, MadathilSC, Orlikowski D, Polkey MI, Roberts M, Tiddens HA, et al. Maximum inspiratory pressure as a clinically meaningful trial endpoint for neuromuscular diseases: a comprehensive review of the literature. Orphanet J Rare Dis 2017 Mar;12(1):52.

12. Fromageot C, Lofaso F, Annane D, Falaize L, Lejaille M, Clair B, Gajdos P, Raphaël JC. Supine fall in lung volumes in the assessment of diaphragmatic weakness in neuromuscular disorders. Arch Phys Med Rehabil 2001 Jan;82(1):123-128.

13. Maitre B, Similowski T, Derenne JP. Physical examination of the adult patient with respiratory diseases: inspection and palpation. Eur Respir J 1995 Sep;8(9):1584-1593.

14. Misuri G, Lanini B, Gigliotti F, Landelli L, Pizzi A, Bertolini MG, Scano G. Mechanism of $\mathrm{CO}_{2}$ retention in patients with neuromuscular disease. Chest 2000 Feb;117(2):447-453.

15. Kreitzer SM, Saunders NA, Tyler HR, Ingram RH Jr. Respiratory muscle function in amyotrophic lateral sclerosis. Am Rev Respir Dis 1978 Mar;117(3):437-447.

16. Polkey MI, Lyall RA, Yang K, Johnson E, Leigh PN, Moxham J. Respiratory muscle strength as a predictive biomarker for survival in amyotrophic lateral sclerosis. Am J Respir Crit Care Med 2017 Jan;195(1):86-95.

17. Neukirch F, Weitzenblum E, Liard R, Korobaeff M, Henry C, Oroven-Frija E, Kauffmann F. Frequency and correlates of sawtooth pattern of flow-volume curves in an epidemiological survey. Chest 1992 Feb;101(2):425-431.

18. Gaig C, Iranzo A. Sleep-disordered breathing in neurodegenerative diseases. Curr Neurol Neurosci Rep 2012 Apr;12(2):205-217.

19. Kimura K, Tachibana N, Kimura J, Shibasaki H. Sleepdisordered breathing at an early stage of amyotrophic lateral sclerosis. J Neurol Sci 1999 Mar;164(1):37-43.

20. Ferguson KA, Strong MJ, Ahmad D, George CF. Sleep disordered breathing in amytrophic lateral sclerosis. Chest 1996 Sep;110(3):664-669.

21. Skatrud J, Iber C, McHugh W, Rasmussen H, Nicholas D. Determinants of hypoventilation during wakefulness and sleep in diaphragmatic paralysis. Am Rev Respir Dis 1980 Mar;121(3):587-593.

22. White JE, Drinnan MJ, Smithson AJ, Griffiths CJ, Gibson GJ. Respiratory muscle activity and oxygenation during sleep in patients with muscle weakness. Eur Respir J 1995 May;8(5): 807-814.

23. Gay PC, Westbrook PR, Daube JR, Litchy WJ, Windebank AJ, Iverson R. Effects of alterations in pulmonary function and sleep variables on survival in patients with amyotrophic lateral sclerosis. Mayo Clin Proc 1991 Jul;66(7):686-694.

24. Lyall RA, Donaldson N, Polkey MI, Leigh PN, Moxham J. Respiratory muscle strength and ventilatory failure in amyotrophic lateral sclerosis. Brain 2001 Oct;124(Pt 10):2000-2013. 